
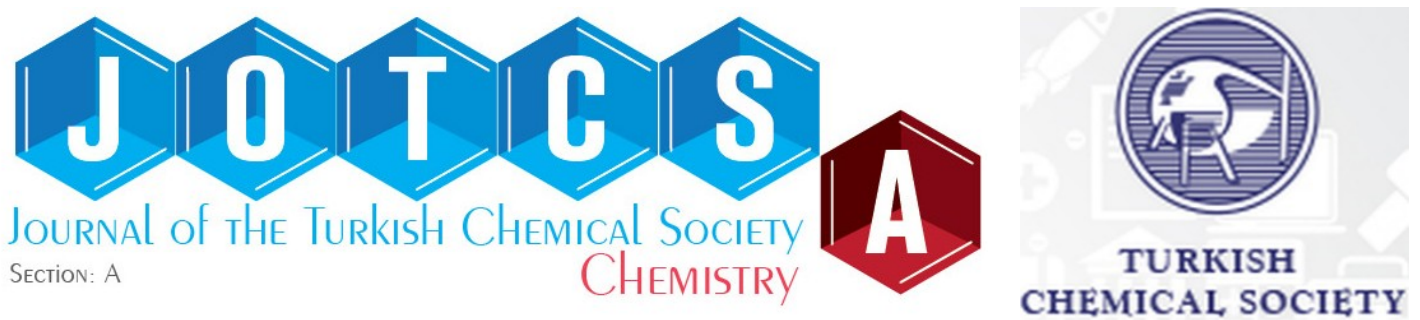

\title{
Ultrasound-Assisted Adsorption of Basic Blue 41 onto Salda mud: Optimization and Error Analysis
}

\begin{abstract}
Elif Tüzün* $\triangle$ ID, Selcan Karakuş
Istanbul University Cerrahpasa, Faculy of Engineering, Department of Chemistry, Avcilar, Istanbul - Turkey.

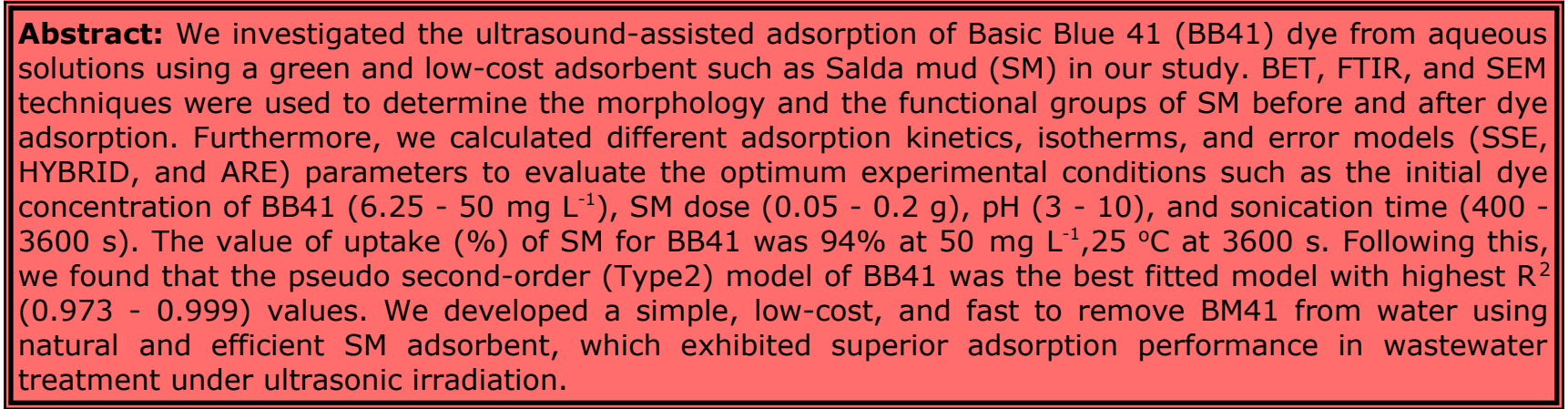

Keywords: Salda mud, ultrasonic-assisted adsorption, error analysis, isotherm models, Basic Blue 41.

Submitted: September 14, 2020. Accepted: November 12, 2020.

Cite this: Tüzün E, Karakuş S. Ultrasound-Assisted Adsorption of Basic Blue 41 onto Salda mud: Optimization and Error Analysis. JOTCSA. 2021;8(1):57-68.

DOI: https://doi.org/10.18596/jotcsa.795083.

*Corresponding author. E-mail: (elif.tuzun@istanbul.edu.tr), Tel: (+90 212473 7000), Fax: (+90 212 $4737180)$.

\section{INTRODUCTION}

Water pollutants such as chemical wastes, dyes, pesticides, radioactive pollutants, and heavy metals), originated from industrial activity and home waste, have become an increasingly global problem for environmental sustainability (1-3). Researchers study to solve accelerating water pollution problems such as physical, chemical, and biological pollution (4). Rapid population growth, unplanned urbanization, unplanned industrialization, and industrial wastewater are the main reasons for water pollution (5). For this reason, the importance of wastewater treatment has become vital for aquatic environments, animals, and humans (6-7). The low-cost based treatment, operation simplicity, and green chemistry play an important role in the treatment of textile-based dye wastewater (8-10). Studies have reported that different methods (oxidation, filtration, ion exchange, adsorption, coagulation-flocculation, and ultrasound-assisted adsorption) can be used to remove textile dyes from aqueous medium (11-16). The ultrasound-assisted adsorption is an effective and rapid method used to remove textile dyes from aqueous medium using ultrasonic technology (16-18).

In recent years, interest in natural, effective and low-cost adsorbents such as microalgae (19), gumbased hydrogel (20), alginate (21), bentonite (22), sediment (23), activated carbon (24), and mud (25) increase to be used to remove dyes from wastewater. The adsorptive characteristics of different types of muds were proposed as natural, low-cost, available in large quantities, and efficient adsorbents for dye removal (26-28).

We preferred Salda mud (SM) as a green adsorbent which is obtained from Salda Lake region of Turkey, and consists of hydromagnesite stromatolites to remove BB41 from aqueous solution using the ultrasound-assisted adsorption method as a function 
of the initial BB41 dye concentration, SM dose, temperature, and $\mathrm{pH}$. Brunauer - Emmett - Teller (BET), Fourier-transfor infrared (FTIR), and Scanning Electron Microscopy (SEM) techniques were used to determine the morphology and the functional groups of SM before and after dye adsorption. According to reported studies on adsorption of dye, we have found that the ultrasound-assisted adsorption method is preferred to remove BB41 from aqueous solution, but there are limited studies on adsorption capacity of SM. In our study, the novelty was to research the ultrasonic-assisted adsorption of BB41 on the surface of SM due to the effect of sonic waves. According to our results, the value of uptake (\%) of BB41 was calculated $94 \%$ at optimized ultrasoundassisted conditions (SM dose $=0.05 \mathrm{~g}$, sonication time $=3600 \mathrm{~s}$, $\mathrm{pH}=7$, the initial BB41 concentration $=50 \mathrm{mg} \mathrm{L}^{-1}$ of BB41). We used different kinetic models such as first order, pseudosecond order (Type 1) and pseudo-second order (Type 2) models to find the kinetic parameters of models and adsorption capacity of SM. This ultrasound-assisted adsorption mechanism is in agreement with the Freundlich model $\left(R^{2}: 0.999\right)$ and pseudo-second-order (Type 2) ( $R^{2}: 0.973$ $0.999)$ with high correlation constants $\left(R^{2}\right)$ and low error parameters. The experimental results showed that SM has great potential as a green adsorbent for the rapid removal of $\mathrm{BB} 41$ from the aqueous medium under ultrasonic power.

\section{EXPERIMENTAL SECTION}

\section{Materials}

BB41 $\left(\mathrm{C}_{20} \mathrm{H}_{26} \mathrm{~N}_{4} \mathrm{O}_{6} \mathrm{~S}_{2}\right.$, molecular weight: 482.57 $\mathrm{g} / \mathrm{mol}$ ) was purchased from Sigma Aldrich Company (Germany). SM was provided from Salda Lake (Burdur, Turkey), washed three times with water before use, then filtered and dried at $50 \pm 1^{\circ} \mathrm{C}$ for $8 \mathrm{~h}$ in a vacuum oven until a constant weight of the sample. The powder was passed through a sieve (200 mesh) and then it was stored for use in the desiccator at room temperature.

\section{Characterization}

SEM device was a Hitachi SU3500, and FTIR was PerkinEImer ${ }^{\circ}$ 's Spectrum $3^{\mathrm{TM}}$ Infrared Spectrometer and spectra were recorded in potassium bromide $(\mathrm{KBr})$ powder within the spectral range 4000 to 600 $\mathrm{cm}^{-1}$ with a resolution of $4 \mathrm{~cm}^{-1}$ and 8 scans were averaged. Characterization of the samples was performed before and after dye adsorption. The ultraviolet-visible (double beam UV-visible) spectrophotometer (T80 \& T80+ - PG Instruments) was used to view the absorbance. BET (Micromeritics ASAP 2020 analyzer) analysis was used to determine the specific surface area of SM.

\section{Ultrasonic-Assisted Adsorption Experiments}

In light of our experimental data, we investigated the selected operating parameters on the ultrasonic- assisted adsorption study was performed to adsorption of BB41. Experimental runs were carried out at constant temperature with the initial BB41 concentration (6.25 - $\left.50 \mathrm{mg} \mathrm{L}^{-1}\right)$, SM dose (0.05 $0.2 \mathrm{~g})$, and $\mathrm{pH}(3-10)$ in ultrasonic bath at $20 \mathrm{kHz}$. Before the measurement of absorbance, the samples were centrifuged at $10,000 \mathrm{rpm}$ (rotor speed) for $5 \mathrm{~min}$ and measured at a certain wavelength $\left(\lambda_{\max }=617 \mathrm{~nm}\right)$ using a ultraviolet-visible spectrophotometer. All measurement runs were done in triplicate under the same experimental conditions.

\section{Calculations Part}

We calculated the value of equilibrium adsorption capacity of SM by the following formula (Eq. 1) (2930):

$$
q_{e}=\left(C_{0}-C_{e}\right) \times \frac{V}{m}
$$

where qe: the equilibrium adsorption capacity of SM $\left(\mathrm{mg} \mathrm{g}^{-1}\right), \mathrm{V}$ : volume of BB41 solution (L), $\mathrm{m}$ : mass of the SM $(\mathrm{g}), \mathrm{C}_{0}$ : the initial BB41 concentrations (mg $\mathrm{L}^{-1}$ ), and $\mathrm{Ce}$ : the equilibrium BB41 concentrations $\left(\mathrm{mg} \mathrm{L}^{-1}\right)$.

The kinetic experimental runs were performed at the similar optimized conditions (the initial BB41 concentration $\left(6.25\right.$ - $\left.50 \mathrm{mg} \mathrm{L}^{-1}\right)$, SM dose (0.05 $0.2 \mathrm{~g})$, and medium $\mathrm{pH}(3-10)$ in ultrasonic bath at $20 \mathrm{kHz}$ ). We used different kinetic models such as first order, pseudo-second order (Type 1) and pseudo-second order (Type 2) models to find the kinetic parameters of models and adsorption capacity of SM. The parameters of kinetic models were calculated by the following formulas (Eqs. 2-4) $(31-33)$ :

first order model:

$$
\log \left(q_{e}-q_{t}\right)=\log q_{e}-\left(\frac{k_{1}}{2.303}\right) \times t
$$

pseudo-second order model (Type 1):

$$
\frac{t}{q_{t}}=\left(\frac{1}{h}\right)-\frac{t}{q_{e}}
$$

pseudo-second order model (Type 2):

$$
\frac{1}{q_{t}}=\left(\frac{1}{h}\right) \frac{1}{t}+\frac{1}{q_{e}}
$$

Where qt : the amount of measured adsorption capacity of SM $\left(\mathrm{mg} \mathrm{g}^{-1}\right)$ at time $\mathrm{t}$, $\mathrm{t}$ : time $(\mathrm{min}), \mathrm{k}_{1}$ : the rate constant of the pseudo-first order model $\left(\min ^{-1}\right), \mathrm{h}: \mathrm{k}_{2} \mathrm{q}_{\mathrm{e}}{ }^{2}, \mathrm{k}_{2}$ : the rate constant of the pseudo-second order model $\left(\mathrm{g} \mathrm{mg}^{-1} \mathrm{~min}^{-1}\right)$, and $\mathrm{k}_{\mathrm{ip}}$ : the rate constant of intra-particle diffusion model $\left(\mathrm{mg} / \mathrm{g} \min ^{1 / 2}\right)$.

Adsorption isotherms experiments were performed at initial dye (BB41) concentration (6.25-50 $\mathrm{mg} \mathrm{L}^{-1}$ ) 
and SM dose $(0.05 \mathrm{~g})$ at solution $\mathrm{pH}$ 7.0. Different isotherm parameters (Langmuir, Freundlich, Temkin, Harkins - Jura, and Halsey parameters) were calculated using Eqs. 5-9, respectively (3436).

$$
\begin{aligned}
& \frac{1}{q_{e}}=\frac{1}{q_{t}}+\frac{1}{q_{t} K_{L}} \times \frac{1}{C_{e}} \\
& \ln q_{e}=\ln K_{F}+n \ln C_{e} \\
& q_{e}=K_{t} T \ln a_{T}+K T \ln C_{e} \\
& \frac{1}{q_{e}^{2}}=\frac{B}{A}-\frac{1}{A} \log C_{e} \\
& \ln q_{e}=\frac{1}{n} \ln k-\frac{1}{n} \ln C_{e}
\end{aligned}
$$

Where, $\mathrm{K}_{\mathrm{L}}$ : the Langmuir constant $\left(\mathrm{L} \mathrm{mg}^{-1}\right), \mathrm{K}_{\mathrm{F}}$ : the Freundlich constant $\left(\mathrm{mg} \mathrm{g}^{-1}\right), 1 / \mathrm{n}$ : the intensity of adsorption, $\mathrm{K}_{\mathrm{T}}$ : the Temkin constant $\left(\mathrm{L} \mathrm{g}^{-1}\right), \mathrm{K}_{\mathrm{T}}=\mathrm{R}$ $\mathrm{T} / \mathrm{b}, \mathrm{T}$ : the temperature $(\mathrm{K}), \mathrm{A}$ and $\mathrm{B}$ : Halsey constant, and $\mathrm{R}$ : the universal gas constant (8.314 $\mathrm{J} / \mathrm{mol} \mathrm{K}$ ).

We calculated the error analysis parameter to find the best fitted kinetic models. The formulas of the sum of squares of errors (SSE), the hybrid fractional error function (HYBRID), and the average relative error (ARE) models were given Eq. 10-12, respectively (37-38).

$$
\begin{gathered}
\sum_{i=1}^{n}\left(q_{c a l}-q_{e}\right)_{i}^{2} \\
\frac{100}{n-p} \sum_{i=1}^{n}\left(\frac{\left(q_{e}-q_{c a l}\right)_{i}^{2}}{q_{e}}\right) \\
\frac{100}{n-p} \sum_{i=1}^{n}\left(\frac{q_{e}-q_{c a l}}{q_{e}}\right)_{i}
\end{gathered}
$$

Where $\mathrm{q}_{\mathrm{e}}$ is the experimental capacity of the adsorbent, qcal is the calculated capacity of the adsorbent, $\mathrm{n}$ is the number of data, and $\mathrm{p}$ is the number of parameters in the experiment.

\section{RESULTS AND DISCUSSION}

Characterizations of SM before and after BB41 adsorption

The main objective of this paper was to illuminate the adsorption behavior of SM for removal of BB41 dye using the ultrasonic-assisted adsorption method. Many previous studies have been reported about BB41 adsorption kinetics, but limited works have been reported on the adsorption characteristic of SM under the acoustic cavitation, but limited works have been reported on the adsorption characteristic of SM under the acoustic cavitation. The surface area of SM was given $20.12 \mathrm{~m}^{2} / \mathrm{g}$ (5) and the value of specific surface area was $0.022 \mathrm{~m}^{2} /$ $g$ of SM for after adsorption process. BET results demonstrated that BB41 was adsorbed onto SM. SEM images of the surface of SM before and after BB41 adsorption at different magnifications were given in Figure 1 (a-b). In Fig. 3.1, SEM results showed that the unloaded SM had an irregular and heterogeneous porous surface. After the adsorption process, the surface of SM was covered with BB41 dye and the surface of SM became smooth in a short time. According to results, we assumed there were physico-chemical adsorption mechanisms on the surface of SM. As a result of these differences between SEM results, we determined that BB 41 was physico-chemically adsorbed on the surface of SM and this result was supported by UV and FTIR results.

According to FTIR results of SM, we reported that the adsorbent had characteristic peaks at 3441.35 $\mathrm{cm}^{-1}(-\mathrm{OH})$, at $1477.21 \mathrm{~cm}^{-1}\left(\mathrm{CH}_{3}\right.$ bending), at $1417.42 \mathrm{~cm}^{-1}$ (C-H asymmetric bending vibration), and at $1006.66 \mathrm{~cm}^{-1}(\mathrm{Si}-\mathrm{O}-\mathrm{Si})$, respectively. These results were similar with our previous FTIR results of the adsorbent (5). After the adsorption process, we noticed that the characteristic peaks of SM/BB41 were observed at $3441.35 \mathrm{~cm}^{-1}(-\mathrm{OH}$ peak), at $1477.21 \mathrm{~cm}^{-1}\left(\mathrm{CH}_{3}\right.$ bending), at $1416.46 \mathrm{~cm}^{-1}(\mathrm{C}-\mathrm{H}$ asymmetric bending vibration), at $1007.62 \mathrm{~cm}^{-1}$ (Si-O-Si), and $884.20 \mathrm{~cm}^{-1}$ ( $\left.\mathrm{Si}-\mathrm{O}-\mathrm{Si}\right)$, respectively. According to results of FTIR, we noticed that there was no prominent differences in peaks of before / after BB41 ultrasonic-assisted adsorption process. These FTIR results showed that the adsorption process was a physical one which was related to the weak electrostatic interaction and Van der Waals forces. It was determined that our results were consistent with similar studies (48).

\section{Ultrasonic-assisted Adsorption Study Effect of the Initial BB41 Dye Concentration}

During the last years, the ultrasound-assisted adsorption of textile dyes have been considered by some of researchers under ultrasound irradiation with $20-100 \mathrm{kHz}$ ultrasonic waves at $25-40^{\circ} \mathrm{C}$ for 5 - $60 \min (39-42)$. The initial dye concentration has an impact on the adsorption characteristic of adsorbent under ultrasonic irradiation. The effect of the initial BB41 concentration on the uptake percentage was presented in Figure 3 (a-d). 


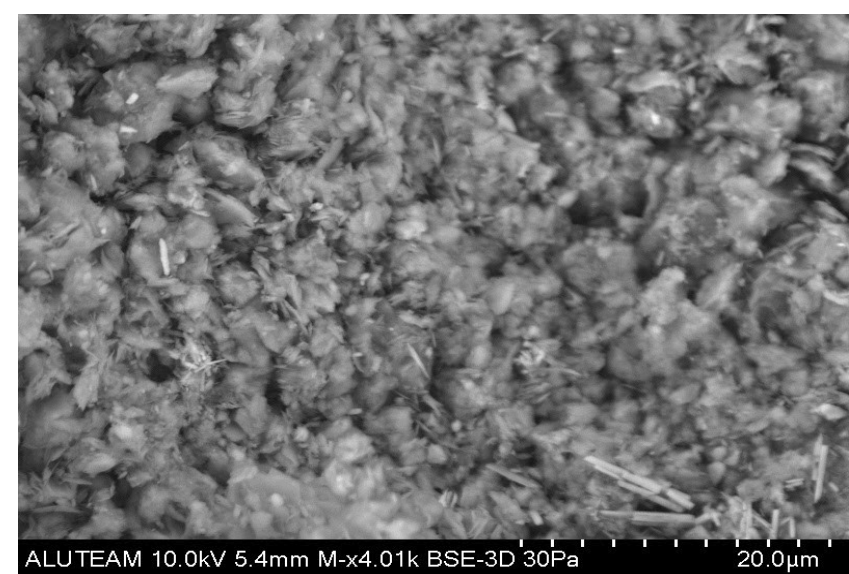

(a)

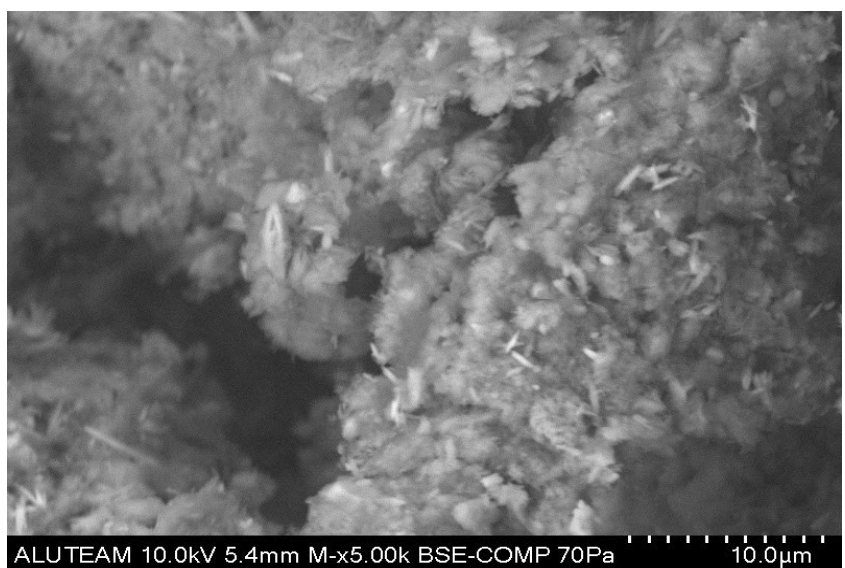

(b)

Figure 1: SEM images of SM (a) before and (b) after BB41 adsorption.

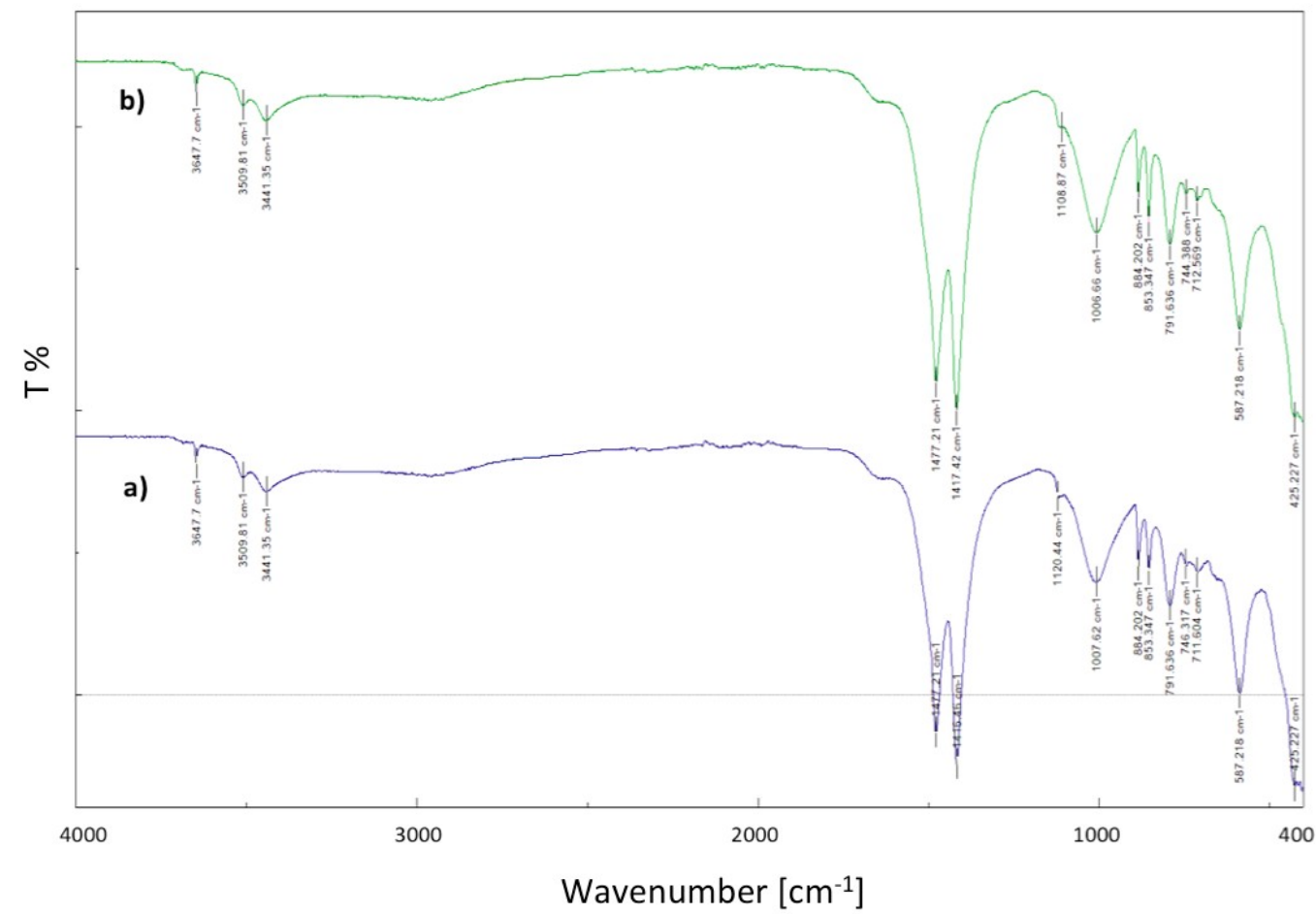

Figure 2: FTIR spectra of SM (a) before and (b) after BB41 adsorption.

In the present study, we used FTIR technique to shed light on the chemical structure and functional groups of SM on a) before and b) after BB41 ultrasonic-assisted adsorption process and FTIR graphs of samples were given in Figure 2.

In Figure 3, it was shown that the value of qe of BB41 increased with increasing $M B$ initial dye concentration $\left(6.25-50 \mathrm{mg} \mathrm{L}{ }^{-1}\right.$ ) at $25^{\circ} \mathrm{C}$, and the maximum equilibrium adsorption capacities of SM were calculated to be $233 \mathrm{mg} / \mathrm{g}, 828 \mathrm{mg} / \mathrm{g}, 1862$ $\mathrm{mg} / \mathrm{g}$, and $4699 \mathrm{mg} / \mathrm{g}$ for $6.25 \mathrm{mg} \mathrm{L}^{-1}, 12.5 \mathrm{mg} \mathrm{L}^{-1}$, $25 \mathrm{mg} \mathrm{L}^{-1}$ and $50 \mathrm{mg} \mathrm{L}^{-1}$, respectively. We determined that the ultrasound irradiation played a major factor in the adsorption of the BB41 from the aqueous medium onto the surface of SM with $1 \mathrm{~h}$ sonication time. As a result, we assumed that qe of SM increased with the initial BB41 concentration due to the amount of BB41 molecules adsorbed onto the active surface sites of SM (43). 


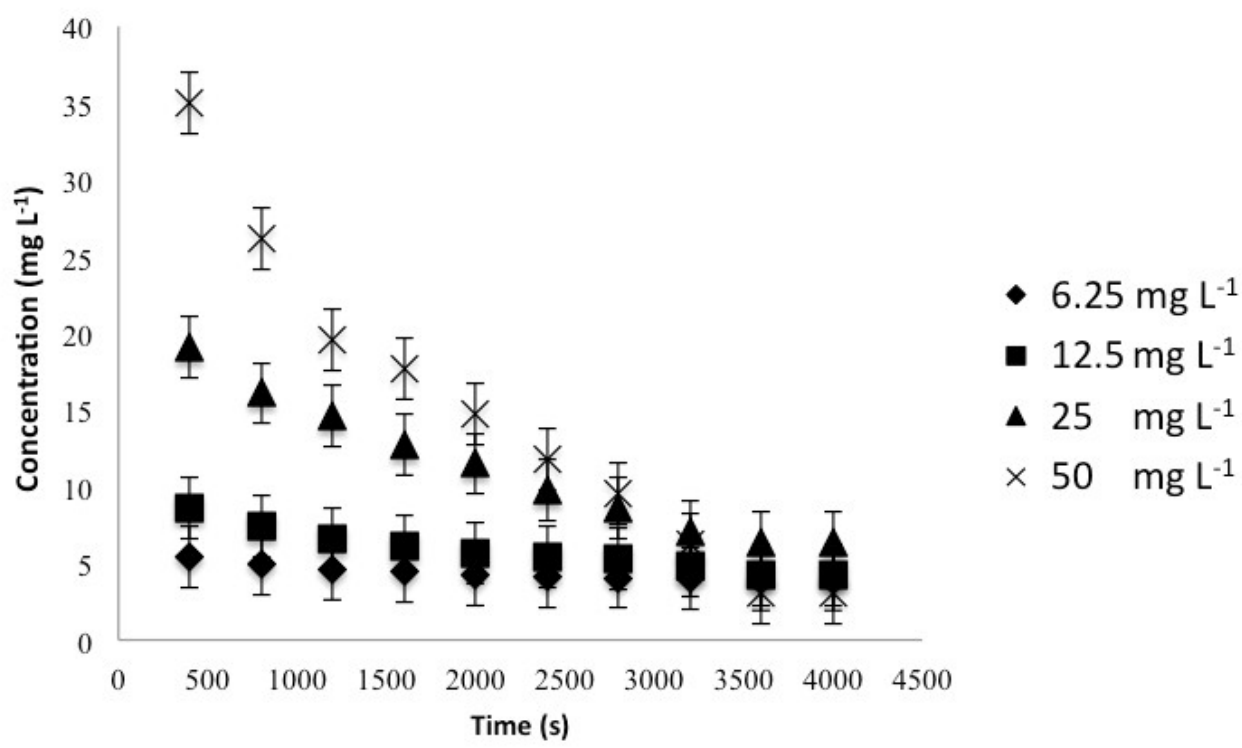

Figure 3: Effect of the initial dye concentration on the adsorption of BB41 onto SM (adsorbent dosage: 0.05 g, temperature: $25^{\circ} \mathrm{C}$, and $\mathrm{pH}: 7$ ).

\section{Effect of SM Dose}

In this study, we investigated the different SM doses in the range of $0.05-0.2 \mathrm{~g}$ in the ultrasound-assisted adsorption of BB41 from aqueous solutions (at pH 7, $25^{\circ} \mathrm{C}$ and $20 \mathrm{kHz}$ ) and experimental results were given in Figure 4 (a-d).

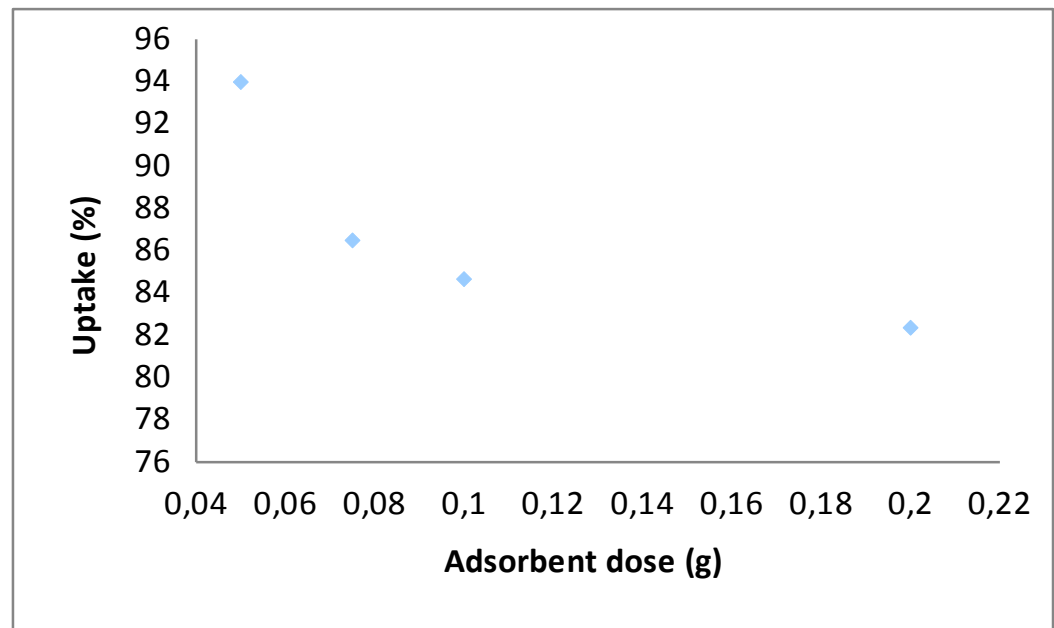

Figure 4: Effect of the adsorbent dose on the adsorption of BB41 onto SM (the initial dye concentration: 50 $\mathrm{mg} \mathrm{L}^{-1}$, temperature: $25^{\circ} \mathrm{C}$, and $\mathrm{pH}: 7$ ).

According to the results, we showed that the adsorption capacities of SM were changed with the SM dose and adsorption was higher at low SM dose (uptake percentages:93.97\% for $0.05 \mathrm{~g}$ of $\mathrm{SM}$ ) (44).

\section{Effect of pH Medium}

In this work, we investigated the effect of $\mathrm{pH}$ medium range of (3-10) on BB41 adsorption mechanism onto the surface of SM and results were given in Fig. 3.5 (a-d). Depending on the results, the maximum uptake percentage of SM was measured at $\mathrm{pH} 7$.
At lower the values of $\mathrm{pH}$, the electrostatic repulsive force has an effect on the uptake percentages of SM and dyes removal efficiency due to the positive charges (45). Consequently, the optimum $\mathrm{pH}$ was 7.0 for adsorption experimental runs.

\section{Effect of Sonication Time}

In order to achieve the optimized operating conditions, we focused on the effect of the sonication time in the range of (400 - $3600 \mathrm{~s})$ on adsorption process and evaluated the effects of the sonication time on the uptake percentages of SM. We compared the values of the uptake percentages of SM under ultrasonic irradiation in Figure 6. 


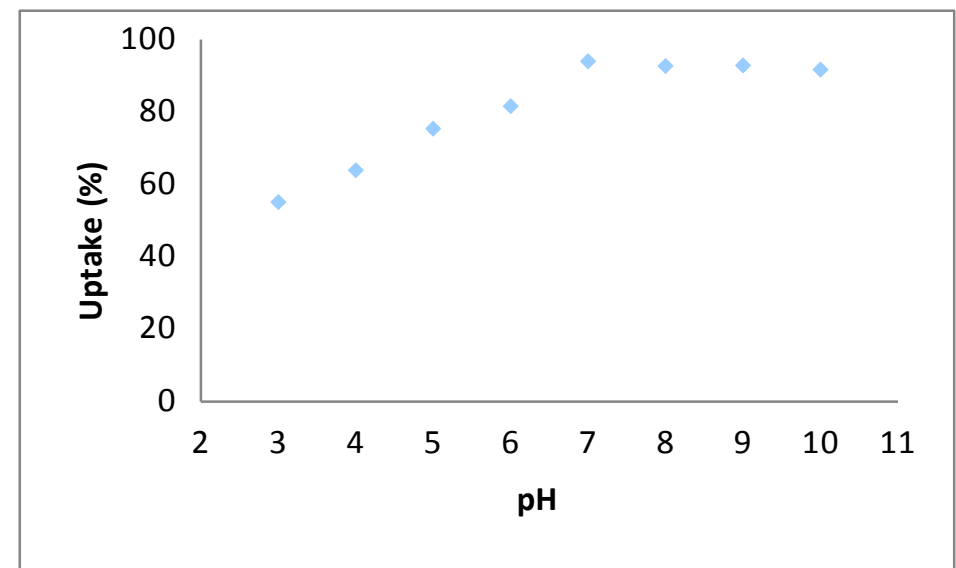

Figure 5: Effect of the $\mathrm{pH}$ on the adsorption of BB41 onto SM (the initial dye concentration: $50 \mathrm{mg} \mathrm{L}^{-1}$, temperature: $25^{\circ} \mathrm{C}$, and adsorbent dosage: $0.05 \mathrm{~g}$ ).

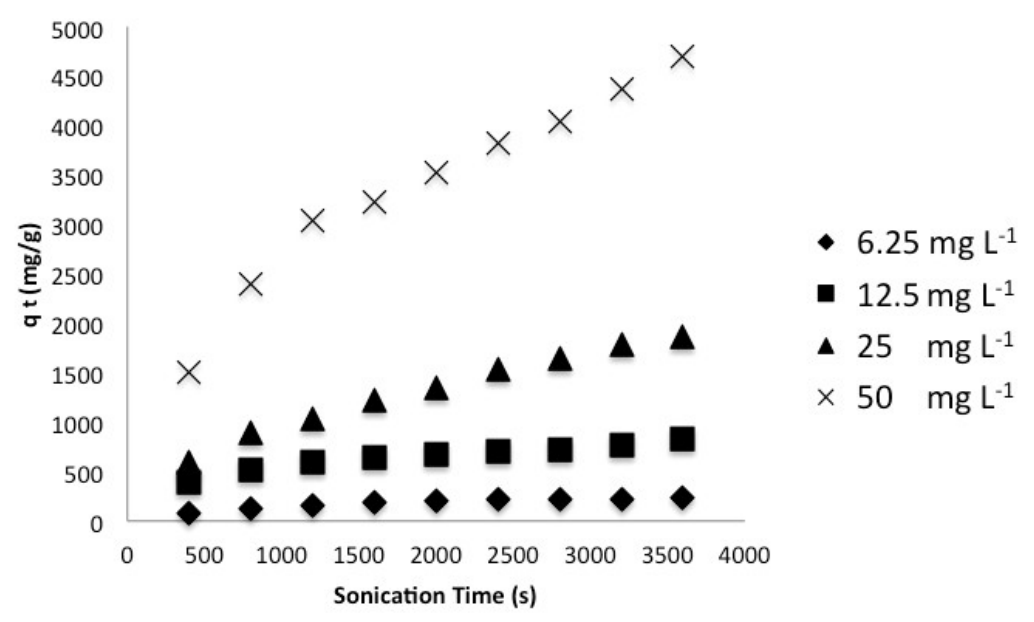

Figure 6: Effect of the sonication time on the adsorption of BB41 onto SM (temperature: $25^{\circ} \mathrm{C}$, and adsorbent dosage: $0.05 \mathrm{~g}$ ).

The initial BB41 concentration increased from 6.25 to $50 \mathrm{mg} \mathrm{L}^{-1}$, while the dye adsorption capacity onto SM increased from 232.75-4698.66 $\mathrm{mg} / \mathrm{g}$. The results showed that the sonication time enhanced qe of the adsorbent due to the synergic mechanism of the ultrasonic adsorption process (46).

\section{Kinetic Studies}

The kinetic model parameters of adsorption systems were calculated to understand the ultrasoundassisted adsorption mechanism and to optimize the adsorption process. For this purpose, several kinetic models such as first order, pseudo-second order (Type 1) and pseudo-second order (Type 2) models were compared to examine the ultrasound-assisted adsorption process of BB41 onto SM (0.05 g of adsorbent dosage) from the different initial dye concentrations in the range of $6.25-50 \mathrm{mg} \mathrm{L}^{-1}$ and at $25{ }^{\circ} \mathrm{C}$. Also we evaluated the mechanism of ultrasound-assisted adsorption process consisting of the mass transfer, diffusion and chemical reaction with these models were calculated by Eqs. 2.2-2.4 kinetic models. The results of experimental kinetic studies of BB41 adsorption at different initial BB41 dye concentrations were indicated in Figure 7, and the corresponding kinetic model parameters obtained for each model were given in Table 1. According to the correlation coefficients $\left(R^{2}>0.99\right)$ of models obtained for each kinetic model, the pseudo-second-order model (Type 2) was the most suitable to explain the BB41 adsorption reaction of SM. The linear graphs of the pseudo-second-order (Type 2) model for the BB41 adsorption onto the surface of SM were given in Figure 7. Consequently, the chemical reaction of BB41 dye with the surface of SM was the rate-limiting step in the ultrasoundassisted dye adsorption (47). 


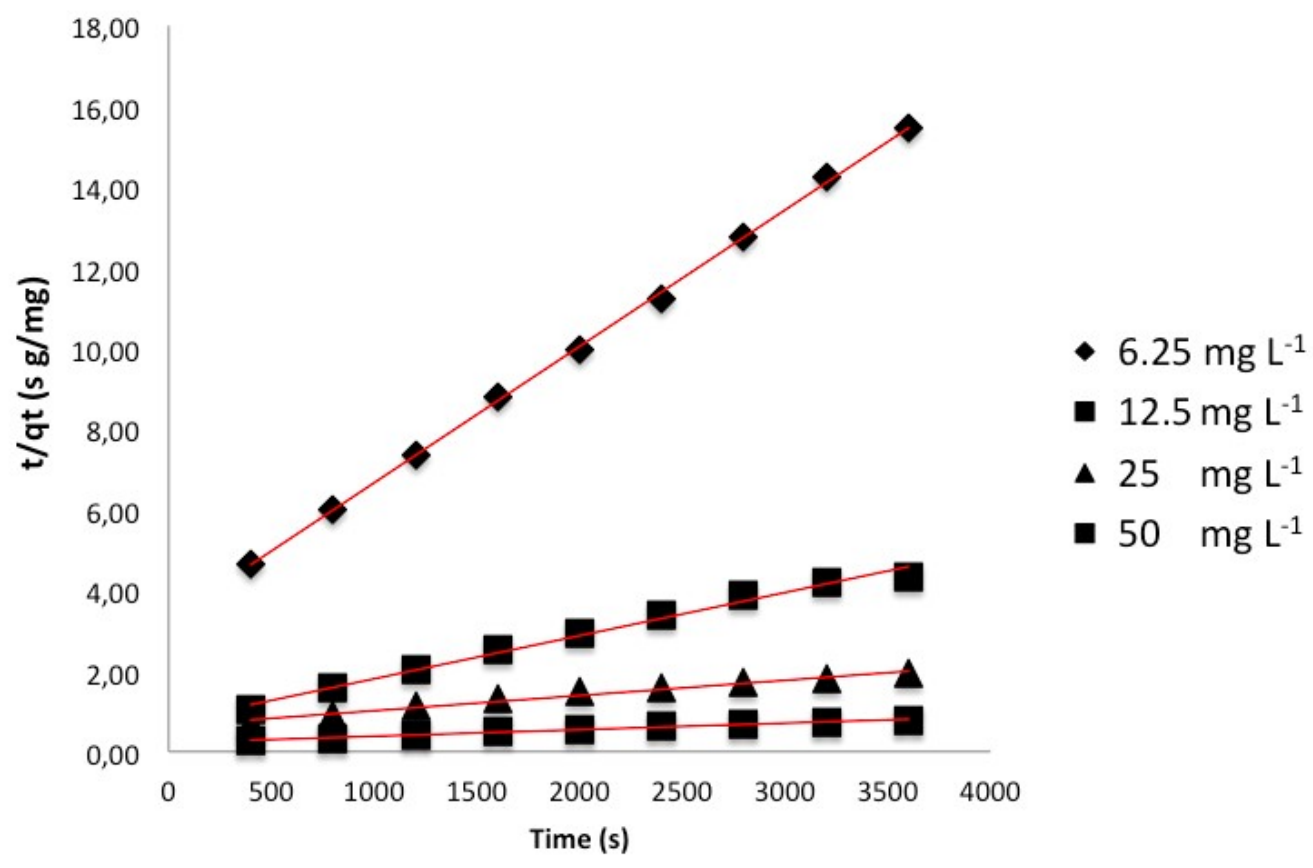

Figure 7: A pseudo-second order kinetic model (Type 2) of BB41 onto SM at different initial dye concentrations.

Table 1. Adsorption kinetic model parameters for the BB41 adsorption on SM at at different initial dye concentrations.

\begin{tabular}{|c|c|c|c|c|c|c|c|c|}
\hline \multirow[t]{2}{*}{ Adsorbent } & \multirow[b]{2}{*}{$C\left(g^{-1}\right)$} & \multirow[b]{2}{*}{$\begin{array}{l}\text { Uptake } \\
(\%)\end{array}$} & \multirow[b]{2}{*}{$\begin{array}{l}\text { qe, exp } \\
(\mathrm{mg} / \mathrm{g})\end{array}$} & \multicolumn{3}{|c|}{$\begin{array}{c}\text { Second order model } \\
\text { (Type 2) }\end{array}$} & \multirow{2}{*}{\begin{tabular}{l}
$\begin{array}{l}\text { Second } \\
\text { order } \\
\text { model } \\
\text { (Type 1) }\end{array}$ \\
\multicolumn{1}{c}{$\mathrm{R}^{2}$} \\
\end{tabular}} & \multirow{2}{*}{$\begin{array}{c}\begin{array}{l}\text { First } \\
\text { order } \\
\text { model }\end{array} \\
\mathrm{R}^{2} \\
\end{array}$} \\
\hline & & & & $\begin{array}{l}\text { qe, cal } \\
(\mathrm{mg} / \mathrm{g})\end{array}$ & $\mathrm{k}_{2}$ & $\mathrm{R}^{2}$ & & \\
\hline \multirow[t]{4}{*}{ SM } & 6.25 & 37.24 & 232.75 & 294.12 & 0.000040 & 0.999 & 0.662 & 0.696 \\
\hline & 12.5 & 66.27 & 828.34 & 833.33 & 0.000020 & 0.990 & 0.665 & 0.682 \\
\hline & 25.0 & 74.47 & 1861.76 & 1999.98 & 0.000015 & 0.986 & 0.896 & 0.891 \\
\hline & 50.0 & 93.97 & 4698.66 & 4998.24 & 0.000012 & 0.982 & 0.895 & 0.890 \\
\hline
\end{tabular}

\section{Isotherm Models}

We compared different adsorption isotherm models to explain a synergetic interaction between BB41 in the aqueous medium and the adsorbed BB41 concentration onto the surface of SM at equilibrium. The adsorption isotherm (Langmuir, Freundlich, Temkin, Harkins - Jura, and Halsey) parameters for the BB41 dye ultrasound-assisted adsorption onto SM were given in Table 2.

According to the experimental results, we found that the Freundlich isotherm model was best fitted with high correlation constants $\left(R^{2}\right)$ (0.999). The ultrasound-assisted adsorption of BB41 onto SM could better explain the mechanism of the heterogeneous system (Figure 8). Furthermore, we calculated the value of $n$ (Freundlich isotherm constant) to show whether the mechanism of adorption was chemical ( $n$ is smaller than 1 ) or physical ( $\mathrm{n}$ is greater than or equal to 1 ). In line with this information, the mechanism adsorption of BB41 dye onto the surface of SM was proven as a physical adsorption process under ultrasonic waves (48).

\section{Optimization and Error Analysis}

In our study, we calculated the different error parameters to optimize the ultrasound-assisted adsorption process of BB41 onto SM and compared different models parameters via SSE, HYBRID, and ARE models. All error results were given in Table 3, and accordingly we proved that the minimum error analysis results of ARE expression with high correlation constant of Freundlich isotherm were compatible. In Table 4, the comparison of the value of adsorption capacity of BB41 with the other adsorbents were given. Consequently, SM 
demonstrate a efficient potential for removal of BB41 in a short time under ultrasound waves.

Table 2. Adsorption isotherm models parameters of BB41 on SM. (The initial dye concentration: $6.25-50$

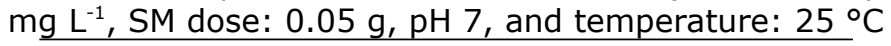

\begin{tabular}{cll}
\hline Models & Parameters & \\
\hline Freundlich & $\mathrm{n}$ & 1.100 \\
& $\mathrm{~K}_{\mathrm{F}}\left(\mathrm{mg}^{\left.1-1 / \mathrm{n} \mathrm{L}^{1 / \mathrm{n}} / \mathrm{g}\right)}\right.$ & 100.01 \\
& $\mathrm{R}^{2}$ & 0.999 \\
\hline Langmuir & $\mathrm{q}_{\mathrm{m}}(\mathrm{mg} / \mathrm{g})$ & 0.25 \\
& $\mathrm{~K}_{\mathrm{L}}(\mathrm{mg} /)^{-}$ & 4.67 \\
& $\mathrm{R}^{2}$ & 0.993 \\
\hline Temkin & $\mathrm{K}_{\mathrm{T}}(\mathrm{kJ} / \mathrm{mol})$ & 1423.5 \\
& $\mathrm{a}_{\mathrm{T}}(\mathrm{Lm} / \mathrm{g})$ & 2.72 \\
& $\mathrm{R}^{2}$ & 0.907 \\
\hline Harkins - & $\mathrm{A}_{\mathrm{H}}$ & 20.000 \\
Jura & & \\
& $\mathrm{B}_{\mathrm{H}}$ & 0.00001 \\
& $\mathrm{R}^{2}$ & 0.751 \\
\hline Halsey & $\mathrm{n}_{\mathrm{H}}$ & 1.10 \\
& $\mathrm{~K}$ & 100.02 \\
& $\mathrm{R}^{2}$ & 0.998 \\
\hline
\end{tabular}

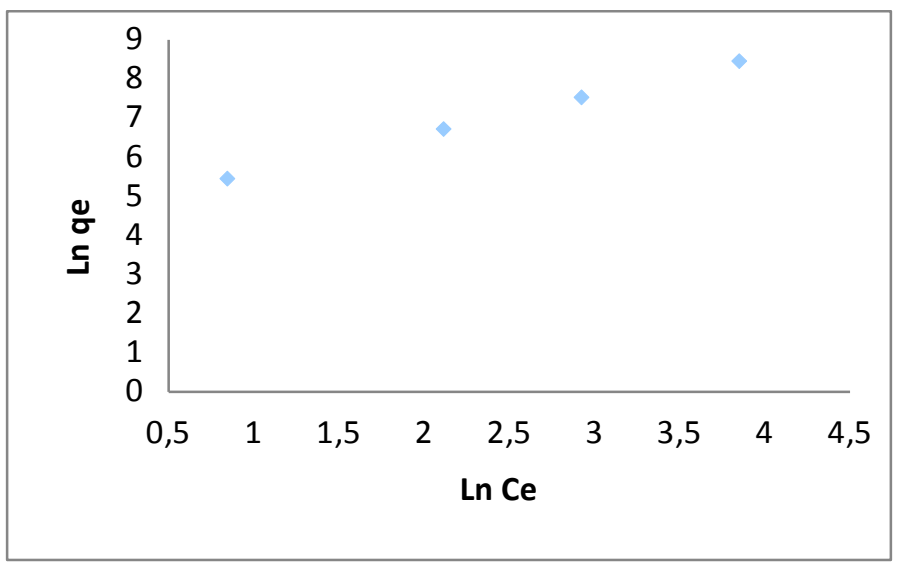

Figure 8: Freundlich isotherm model of BB41 on the adsorption of SM (The initial BB41 concentration:

6.25-50 $\mathrm{mg} \mathrm{L}^{-1}$, adsorbent dose: $0.05 \mathrm{~g}, \mathrm{pH} 7$, and temperature: $25^{\circ} \mathrm{C}$ ).

Table 3: The error results of adsorption isotherm of BB41 onto SM.

\begin{tabular}{ccccc}
\hline Models & $\begin{array}{c}\text { Correlation constants } \\
\left(\mathbf{R}^{\mathbf{2}}\right)\end{array}$ & SSE & HYBRID & ARE \\
\hline Freundlich & 0.999 & 0.994 & 0.996 & $\mathbf{0 . 9 9 8}$ \\
Langmuir & 0.993 & 0.988 & 0.989 & $\mathbf{0 . 9 9 5}$ \\
Temkin & 0.907 & 0.886 & 0.901 & $\mathbf{0 . 9 0 5}$ \\
Harkins - Jura & 0.751 & 0.742 & 0.745 & $\mathbf{0 . 7 4 9}$ \\
Halsey & 0.998 & 0.985 & 0.990 & $\mathbf{0 . 9 9 6}$ \\
\hline
\end{tabular}

Table 4: The comparison of the adsorption capacities values of various adsorbents for BB41 adsorption.

\begin{tabular}{|c|c|c|}
\hline Adsorbent & Adsorption Capacity & Ref \\
\hline Pistachio shell & $41.77 \mathrm{mg} / \mathrm{g}$ & $(48)$ \\
\hline Activated carbon & $125 \mathrm{mg} / \mathrm{g}$ & (49) \\
\hline Photobiocomposite bead & 3.03 to $90.15 \mathrm{mg} / \mathrm{g}$ & (50) \\
\hline Grape bagasse/Silica & $268.1 \mathrm{mg} / \mathrm{g}$ & (51) \\
\hline Brick waste & $60-70 \mathrm{mg} / \mathrm{g}$ & $(52)$ \\
\hline Natural zeolitic tuff & $192.31 \mathrm{mg} / \mathrm{g}$ & (53) \\
\hline Nanoporous silica & $345 \mathrm{mg} / \mathrm{g}$ & (54) \\
\hline Salda mud & $232.75-4698.66 \mathrm{mg} / \mathrm{g}$ & This study \\
\hline
\end{tabular}




\section{CONCLUSIONS}

In this work, we studied the rapid adsorption process of BB41 from aqueous solutions under ultrasonic waves in a short time using the low-cost and efficient adsorbent such as SM. Characteristic functional groups and surface morphologies of SM and SM/BB41 were analyzed using FTIR and SEM techniques. To examine the adsorption mechanism, we calculated the parameters of adsorption kinetic, adsorption isotherm and error models at different experimental conditions (SM dose, $\mathrm{pH}$, and sonication time). According to the experimental results obtained, we proved that the best fitted kinetic model was a pseudo-second order kinetic model and the isotherm model was Freundlich (highest $\mathrm{R}^{2}$ : 0.999 and lowest error data) model. Consequently, we determined that SM was a green, promising, and effective adsorbent and could be used in the environmental applications to remove BB41 dye.

\section{Declaration of Competing Interest}

The authors declare that they have no known competing financial interests or personal relationships that could have appeared to influence the work reported in this paper.

\section{ACKNOWLEDGEMENTS}

The authors would like to thank Fatih Özbaş for assistance of SEM analysis.

\section{REFERENCES}

1. Aksu Z. Application of biosorption for the removal of organic pollutants: a review. Process biochemistry. 2005;40(3-4):997-1026.

2. Zia Z, Hartland A, Mucalo M. Use of low cost biopolymers and biopolymeric composite systems for heavy metal removal from water. International Journal of Environmental Science And Technology. $2020 ; 17: 4389-4406$.

3. Madhav S, Ahamad A, Singh AK, Kushawaha J, Chauhan JS, Sharma $S$, et al. Water Pollutants: Sources and Impact on the Environment and Human Health. In: Pooja D, Kumar P, Singh P, Patil S, editors. Sensors in Water Pollutants Monitoring: Role of Material. Singapore: Springer Singapore; 2020;43-62.

4. Kulal DK, Loni PC, Dcosta C, Some S, Kalambate PK. Cyanobacteria: as a promising candidate for heavy-metals removal. In: Advances in Cyanobacterial Biology. Elsevier; 2020;291-300.

5. Karakuş S, Taşaltın N, Taşaltın C, Kilislioğlu A. Comparative study on ultrasonic assisted adsorption of Basic Blue 3, Basic Yellow 28 and Acid Red 336 dyes onto hydromagnesite stromatolite: kinetic, isotherm and error analysis. Surfaces and Interfaces. 2020;100528.

6. Sismanoglu T, Kismir $Y$, Karakus S. Single and binary adsorption of reactive dyes from aqueous solutions onto clinoptilolite. Journal of Hazardous Materials. 2010;184(1-3):164-9.

7. Gissawong N, Mukdasai S, Boonchiangma S, Sansuk S, Srijaranai S. A rapid and simple method for the removal of dyes and organophosphorus pesticides from water and soil samples using deep eutectic solvent embedded sponge. Chemosphere. 2020;260:127590.

8. Yashni G, Willy K, Al-Gheethi A, Mohamed R, Salleh SM, Hashim M. A Review on Green Synthesis of ZnO Nanoparticles Using Coriandrum Sativum Leaf Extract For Degrading Dyes in Textile Wastewater: A Prospect Towards Green Chemistry. MS\&E. $2020 ; 736(4): 042003$.

9. Joseph J, Radhakrishnan RC, Johnson JK, Joy SP, Thomas J. Ion-exchange mediated removal of cationic dye-stuffs from water using ammonium phosphomolybdate. Materials Chemistry and Physics. 2020;242:122488.

10. Goutam SP, Saxena G, Roy D, Yadav AK, Bharagava RN. Green synthesis of nanoparticles and their applications in water and wastewater treatment. In: Bioremediation of Industrial Waste for Environmental Safety. Springer; 2020;349-79.

11. Ma J, Tang $X, \mathrm{He} Y$, Fan $Y$, Chen J. Robust stable MoS2/GO filtration membrane for effective removal of dyes and salts from water with enhanced permeability. Desalination. 2020;480:114328.

12. Mukhlish $M B$, Khan $M R$, Islam $M$, Nazir $M$, Snigdha J, Akter R, et al. Decolorization of Reactive Dyes from Aqueous Solution Using Combined Coagulation-Flocculation and Photochemical Oxidation $\left(\mathrm{UV} / \mathrm{H}_{2} \mathrm{O}_{2}\right)$. Sustainable Chemical Engineering. 2020;51-61.

13. Jun BM, Kim $S$, Rho $H$, Park CM, Yoon $Y$. Ultrasound-assisted Ti3C2Tx MXene adsorption of dyes: Removal performance and mechanism analyses via dynamic light scattering. Chemosphere, $2020 ; 126827$.

14. Li J, Zhu K, Li R, Fan X, Lin H, Zhang H. The removal of azo dye from aqueous solution by oxidation with peroxydisulfate in the presence of granular activated carbon: Performance, mechanism and reusability. Chemosphere. 2020;259:127400.

15. Jawad AH, Abdulhameed AS, Mastuli MS. Acidfactionalized biomass material for methylene blue dye removal: a comprehensive adsorption and 
mechanism study. Journal of Taibah University for Science. 2020;14(1):305-13.

16. Yu Q, Fan L, Li J. A novel process for asparagus polyphenols utilization by ultrasound assisted adsorption and desorption using resins. Ultrasonics Sonochemistry. 2020;63:104920.

17. Sharifpour E, Ghaedi M, Asfaram A, Farsadrooh M, Dil EA, Javadian $H$. Modeling and optimization of ultrasound-assisted high performance adsorption of Basic Fuchsin by starch-capped zinc selenide nanoparticles/AC as a novel composite using response surface methodology. International Journal of Biological Macromolecules. 2020;152:913-21.

18. Kifayatullah HM, Tahir $H$, Shah AR. Modeling and optimization of ultrasound-assisted adsorption of crystal violet dye by graphene oxide nanoparticles using response surface methodology. International Journal of Environmental Analytical Chemistry. 2020;1-17.

19. Chin JY, Chng LM, Leong SS, Yeap SP, Yasin NHM, Toh PY. Removal of Synthetic Dye by Chlorella vulgaris Microalgae as Natural Adsorbent. Arabian Journal For Science And Engineering. 2020.

20. Pandey S, Do JY, Kim J, Kang M. Fast and highly efficient removal of dye from aqueous solution using natural locust bean gum based hydrogels as adsorbent. International Journal of Biological Macromolecules. 2020;143:60-75.

21. Kazemi J, Javanbakht V. Alginate beads impregnated with magnetic Chitosan@ Zeolite nanocomposite for cationic methylene blue dye removal from aqueous solution. International journal of biological macromolecules. 2020; 154:1426-37.

22. Al-Shahrani S. Phenomena of Removal of Crystal Violet from Wastewater Using Khulays Natural Bentonite. Journal of Chemistry. 2020;2020.

23. Tanji K, Arrahli A, Iboustaten EM, El Gaidoumi A, Kherchafi A, Benabdallah AC, et al. Valorization of Oued Sebou Natural Sediments (Fez-Morocco Area) as Adsorbent of Methylene Blue Dye: Kinetic and Thermodynamic Study. The Scientific World Journal. $2020 ; 2020$.

24. Rahimian $\mathrm{R}$, Zarinabadi $\mathrm{S}$. A review of studies on the removal of methylene blue dye from industrial wastewater using activated carbon adsorbents made from almond bark. Progress in Chemical and Biochemical Research. $2020 ; 3(3): 251-68$.

25. Shi W, Ren H, Huang X, Li M, Tang Y, Guo F. Low cost red mud modified graphitic carbon nitride for the removal of organic pollutants in wastewater by the synergistic effect of adsorption and photocatalysis. Separation and Purification Technology. 2020;237:116477.

26. Zhu $M-X$, Lee $L$, Wang $H-H$, Wang Z. Removal of an anionic dye by adsorption/precipitation processes using alkaline white mud. Journal of Hazardous Materials. 2007;149(3):735-741.

27. Thakare SR, Thakare J, Kosankar P, Pal MR. A chief, industrial waste, Activated Red Mud for subtraction of Methylene blue dye from environment. Materials Today: Proceedings. 2020.

28. Babu AN, Reddy DS, Sharma P, Kumar GS, Ravindhranath K, Mohan GK. Removal of hazardous indigo carmine dye from waste water using treated red mud. Materials Today: Proceedings. 2019;17:198-208.

29. Foo $\mathrm{KY}$, Hameed $\mathrm{BH}$. Insights into the modeling of adsorption isotherm systems. Chemical engineering journal. 2010;156(1):2-10.

30. Markovski JS, \DJokić V, Milosavljević M, Mitrić $M$, Perić-Grujić $A A$, Onjia $A E$, et al. Ultrasonic assisted arsenate adsorption on solvothermally synthesized calcite modified by goethite, a-MnO2 and goethite/a-MnO2. Ultrasonics sonochemistry. 2014;21(2):790-801.

31. Roosta M, Ghaedi M, Shokri N, Daneshfar A, Sahraei R, Asghari A. Optimization of the combined ultrasonic assisted/adsorption method for the removal of malachite green by gold nanoparticles loaded on activated carbon: experimental design. Spectrochimica Acta Part A: Molecular and Biomolecular Spectroscopy. 2014;118:55-65.

32. Jacques RA, Bernardi R, Caovila M, Lima EC, Pavan FA, Vaghetti JC, et al. Removal of Cu (II), Fe (III), and $\mathrm{Cr}$ (III) from aqueous solution by aniline grafted silica gel. Separation Science and Technology. 2007;42(3):591-609.

33. Bagheri AR, Ghaedi M, Asfaram A, Bazrafshan $A A$, Jannesar R. Comparative study on ultrasonic assisted adsorption of dyes from single system onto Fe304 magnetite nanoparticles loaded on activated carbon: experimental design methodology. Ultrasonics sonochemistry. 2017;34:294-304.

34. Zare-Dorabei R, Ferdowsi S, Barzin A, Tadjarodi A. Highly efficient simultaneous ultrasonic-assisted adsorption of $\mathrm{Pb}$ (II), Cd (II), $\mathrm{Ni}$ (II) and $\mathrm{Cu}$ (II) ions from aqueous solutions by graphene oxide modified with 2, 2'-dipyridylamine: central composite design optimization. Ultrasonics sonochemistry. 2016;2016(32):265-76.

35. Hamza W, Dammak N, Hadjltaief $\mathrm{H}$, Eloussaief $M$, Benzina M. Sono-assisted adsorption of cristal 
violet dye onto tunisian smectite clay: Characterization, kinetics and adsorption isotherms. Ecotoxicology and environmental safety. 2018;2018(163):365-71.

36. Gülen J, Akın B, Özgür M. Ultrasonic-assisted adsorption of methylene blue on sumac leaves. Desalination and water treatment. 2016;20(57):9286-95.

37. Demirbas E, Kobya M, Konukman A. Error analysis of equilibrium studies for the almond shell activated carbon adsorption of $\mathrm{Cr}$ (VI) from aqueous solutions. Journal of hazardous materials. 2008;13(154): 787-94.

38. Karakuş S. A Novel ZnO Nanoparticle as Drug Nanocarrier in Therapeutic Applications: Kinetic Models and Error Analysis. JOTCSA. 2019;6(2):11932.

39. Amin $M$, Chetpattananondh $P$, Khan $M$. Ultrasound assisted adsorption of reactive dye-145 by biochars from marine Chlorella sp. extracted solid waste pyrolyzed at various temperatures. Journal of Environmental Chemical Engineering. 2009;16(4):557-63.

40. Milenković DD, Dašić PV, Veljković VB. Ultrasound-assisted adsorption of copper(II) ions on hazelnut shell activated carbon. Ultrasonics Sonochemistry. 2009;16(4):557-63.

41. Asfaram A, Ghaedi M, Goudarzi A, Rajabi M. Response surface methodology approach for optimization of simultaneous dye and metal ion ultrasound-assisted adsorption onto $\mathrm{Mn}$ doped $\mathrm{Fe} 3$ O 4 -NPs loaded on AC: kinetic and isothermal studies. Dalton Trans. 2015;44(33):14707-23.

42. Wu Y, Han Y, Tao Y, Fan S, Chu D-T, Ye X, et al. Ultrasound assisted adsorption and desorption of blueberry anthocyanins using macroporous resins. Ultrasonics Sonochemistry. 2018;48:311-20.

43. Sirajudheen $P$, Nikitha $M R$, Karthikeyan $P$, Meenakshi S. Perceptive removal of toxic azo dyes from water using magnetic $\mathrm{Fe} 3 \mathrm{O} 4$ reinforced graphene oxide-carboxymethyl cellulose recyclable composite: Adsorption investigation of parametric studies and their mechanisms. Surfaces and Interfaces. $2020 ; 100648$.

44. Noreen S, Mustafa G, Ibrahim SM, Naz S, Iqbal $M$, Yaseen $M$, et al. Iron oxide (Fe2O3) prepared via green route and adsorption efficiency evaluation for an anionic dye: kinetics, isotherms and thermodynamics studies. Journal of Materials Research and Technology. 2020;9(3):4206-17.

45. Jamshidi M, Ghaedi M, Dashtian K, Hajati S, Bazrafshan AA. Sonochemical assisted hydrothermal synthesis of ZnO: $\mathrm{Cr}$ nanoparticles loaded activated carbon for simultaneous ultrasound-assisted adsorption of ternary toxic organic dye: Derivative spectrophotometric, optimization, kinetic and isotherm study. Ultrasonics Sonochemistry. $2016 ; 32: 119-31$.

46. Wen Z, Huang K, Niu Y, Yao Y, Wang S, Cao Z, et al. Kinetic study of ultrasonic-assisted uranium adsorption by anion exchange resin. Colloids and Surfaces A: Physicochemical and Engineering Aspects. 2020;585:124021.

47. Wei J, Xu J, Mei Y, Tan Q. Chloride adsorption on aminobenzoate intercalated layered double hydroxides: Kinetic, thermodynamic and equilibrium studies. Applied Clay Science. 2020;187:105495.

48. Şentürk İ, Alzein M. Adsorptive removal of basic blue 41 using pistachio shell adsorbent Performance in batch and column system. Sustainable Chemistry and Pharmacy. 2020;16:100254.

49. Afshin S, Mokhtari SA, Vosoughi M, Sadeghi $H$, Rashtbari Y. Data of adsorption of Basic Blue 41 dye from aqueous solutions by activated carbon prepared from filamentous algae. Data in Brief. 2018;21:1008-13.

50. Nouri L, Hemidouche S, Boudjemaa A, Kaouah F, Sadaoui Z, Bachari K. Elaboration and characterization of photobiocomposite beads, based on titanium (IV) oxide and sodium alginate biopolymer, for basic blue 41 adsorption/photocatalytic degradation. International Journal of Biological Macromolecules. 2020;151:6684

51. Benvenuti J, Fisch A, dos Santos JHZ, Gutterres M. Silica-based adsorbent material with grape bagasse encapsulated by the sol-gel method for the adsorption of Basic Blue 41 dye. Journal of Environmental Chemical Engineering. 2019;7(5):103342.

52. Kooli F, Yan L, Al-Faze R, Al-Sehimi A. Removal enhancement of basic blue 41 by brick waste from an aqueous solution. Arabian Journal of Chemistry. $2015 ; 8(3): 333-42$.

53. Humelnicu I, Băiceanu A, Ignat M-E, Dulman V. The removal of Basic Blue 41 textile dye from aqueous solution by adsorption onto natural zeolitic tuff: Kinetics and thermodynamics. Process Safety and Environmental Protection. 2017;105:274-87.

54. Zarezadeh-Mehrizi M, Badiei A. Highly efficient removal of basic blue 41 with nanoporous silica. Water Resources and Industry. 2014;5:49-57. 
Tüzün E, Karakuş S. JOTCSA. 2021; 8(1): 57-68. 